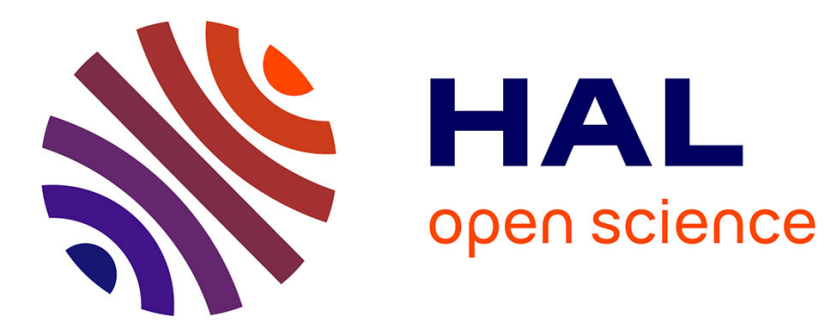

\title{
Ontology-based system for supporting manufacturing sustainability
}

Antonio Giovannini, Alexis Aubry, Hervé Panetto, Michele Dassisti, Hind El

Haouzi

\section{> To cite this version:}

Antonio Giovannini, Alexis Aubry, Hervé Panetto, Michele Dassisti, Hind El Haouzi. Ontology-based system for supporting manufacturing sustainability. Annual Reviews in Control, 2012, 36 (2), pp.309317. 10.1016/j.arcontrol.2012.09.012 . hal-00728192

\section{HAL Id: hal-00728192 \\ https://hal.science/hal-00728192}

Submitted on 5 Sep 2012

HAL is a multi-disciplinary open access archive for the deposit and dissemination of scientific research documents, whether they are published or not. The documents may come from teaching and research institutions in France or abroad, or from public or private research centers.
L'archive ouverte pluridisciplinaire HAL, est destinée au dépôt et à la diffusion de documents scientifiques de niveau recherche, publiés ou non, émanant des établissements d'enseignement et de recherche français ou étrangers, des laboratoires publics ou privés. 


\title{
Ontology-Based System for supporting Manufacturing Sustainability
}

\author{
Antonio Giovannini ${ }^{1,2,3, *}$, Alexis Aubry ${ }^{1,2}$, Hervé Panetto ${ }^{1,2}$, Michele Dassisti ${ }^{4}$, Hind El Haouzi ${ }^{1,2,3}$ \\ ${ }^{1}$ Université de Lorraine, CRAN, UMR 7039, Campus sciences \\ B.P. 70239, Vandouvre-lès-Nancy Cedex, 54506, France \\ (e-mail: \{antonio.giovannini;alexis.aubry;herve.panetto\}@univ-lorraine.fr) \\ ${ }^{2}$ CNRS, CRAN, UMR 7039, France \\ ${ }^{3}$ TRANE SAS, rue des Amériques, 88190 Golbey, France \\ (e-mail: hind.elhaouzi@trane.com) \\ ${ }^{4}$ DIMEG, Politecnico di Bari, Viale Japigia, 70100 Bari, Italy \\ (e-mail: m.dassisti@poliba.it)
}

\begin{abstract}
Sustainability is one of the biggest challenges of this century either for the environment or economical growth. The required cultural shift needs challenging action that will involve deeply software and hardware aspect of manufacturing processes. In this paper, the software part of the matter is addressed by proposing a product centric ontology, in which concepts of product, processes and resources are associated to functions and sustainable manufacturing knowledge. The aim is to design a knowledge-based system that, simulating a sustainable manufacturing expert, is able to automatically identify change opportunities and to propose alternatives on the basis of the existing production scenario.

Keywords: Sustainability, Manufacturing Processes, Knowledge-Based Systems, Expert Systems, Ontology
\end{abstract}

\section{INTRODUCTION}

Today, the introduction of the sustainability concept in industries stresses the need of change towards a more sustainable perspective. The U.S. Department of Commerce defines Sustainable Manufacturing as the creation of manufactured products that use processes that minimize negative environmental impacts, conserve energy and natural resources, are safe for employees, communities, and consumers and are economically sound ${ }^{1}$. From this definition, it is possible to highlight the fundamental roles of the creation of manufactured products and the use of manufacturing processes to obtain the sustainable manufacturing goals (in the three sustainability pillars, economic, social and environmental). In this vision, the most effective way for infusing sustainable manufacturing culture is to support decision makers to shift towards the sustainable manufacturing paradigm. To this purpose, it is possible to simulate the behaviour of a sustainable manufacturing expert that is able to identify opportunities and to design and deploy sustainable manufacturing solutions based on the analysed scenario. For this aim, in this paper, authors propose a model to formalize and relate required concepts for making a knowledge-based system (KBS), a system that is able to identify change opportunities and to support decision makers with the appropriate knowledge for the solutions deployment.

\footnotetext{
${ }^{I}$ U.S. Department of Commerce (2009), available at http://www.trade.gov/competitiveness/sustainable manufacturing/
}

In order to identify change opportunities it is needed to formalize concepts about product, resources and manufacturing processes. Alternatives can be determined only defining limits to proposals: it is necessary to fix what is not changeable. Limits are represented by required functionalities, i.e. obviously it is not allowed to replace a process with another one that provides different outputs. Therefore it is needed to know how product parts, resources and manufacturing processes are related to their functions (why they are used). Doing so, it is possible to assure that the implementation of more sustainable alternative results in a design fulfil the same original requirements. The deployment of the solution involves not only the formalisation of product knowledge. In order to propose changes in an effective way, it is needed to know information about the initial production scenario. Therefore it is needed information that, usually, is stored in different data sources. This heterogeneity can cause semantics losses avoiding the full understanding of relationships between available information.

In order to deal with these issues, in this paper, it is extended a product centric ontology, initially designed for information interoperability, with concepts of functions and sustainable manufacturing. Moreover, it is designed an Ontology-Based System (OBS) that uses formalized knowledge for supporting the design of products and related manufacturing processes. The resulting system is able to exploit knowledge about product, processes, resources and sustainable manufacturing for proposing design and manufacturing process changes.

Next sections are structured as follows: in section 2, existing on concepts of (KBS), ontology and functional representation researches are analysed; in section 3, the

* corresponding author: Antonio.Giovannini@univ-lorraine.fr 
approach for supporting sustainable manufacturing is detailed; in section 4, an industrial case is presented; finally, conclusions are discussed in section 5.

\section{KBS, ONTOLOGIES AND THE CONCEPT OF FUNCTION}

\subsection{KBS for sustainable manufacturing}

From 1976, with the first KBS (or expert system) (Freitas et al., 2005), the growth of this type of systems never stops. A KBS consists of four main components (D. Pham et al., 1988): a knowledge base (KB) containing knowledge about the problem to solve; an inference engine to use the stored knowledge for obtaining solutions from problems; a user interface for justifying resulting solutions; eventually a knowledge acquisition module for developing/updating the system.

Already in 1988, (Iwata, 1988) copes with the status of KBS, most of all in the manufacturing domain. As shown in (Tab.1), the support of design and process planning stages already dealt with a lot of issues, such as understanding of product and production functional requirements, formation of product concept, process and operation planning and so forth.

\section{Tab. 1 - Extract of a table on KBS applications in (Iwata, 1988)}

\begin{tabular}{|c|c|}
\hline $\begin{array}{l}\text { FIELD OF } \\
\text { APPLICATION }\end{array}$ & SUBJECT OF APPLICATION \\
\hline Design & $\begin{array}{l}\text { - Understanding of functional requirements } \\
\text { - Preparation and confirmation of specifications } \\
\text { - Recognition and understanding of specifications } \\
\text { - Examination and determination of basic concept of } \\
\text { design } \\
\text { - Formation of product concept } \\
\text { - Formation of model } \\
\text { - Formation of computational and experimental procedures } \\
\text { - Analysis and simulation of structure } \\
\text { - Inspection of drawings } \\
\text { - Documentation of design }\end{array}$ \\
\hline $\begin{array}{l}\text { Manufacturing } \\
\text { Planning }\end{array}$ & $\begin{array}{l}\text { - Understanding of functional requirements for production } \\
\text { - Formation of manufacturing model } \\
\text { - Process planning } \\
\text { - Operation planning }\end{array}$ \\
\hline
\end{tabular}

In the sustainable manufacturing domain, there was not the same quick growth. Today, most of KBS in the domain of sustainable manufacturing focuses on material and manufacturing alternatives evaluation. The assessment of alternative solutions is often based on a Life-Cycle Assessment (LCA) methodology. (Pineda-Henson et al., 2002) developed a KBS for the green productivity (GP) evaluation. The GP assessment is based on the integration of the LCA methodology and a multi-criteria decision analysis, namely analytic hierarchy process (AHP). LCA technical framework provides decision factors (impact and improvement options) for the evaluation. The AHP gives indexes priority and structure relationships between them. In (Zhou et al., 2009), authors use genetic algorithms (GA) and artificial neural networks (ANN) for a multi-objective optimization of material selection for sustainable products.
GA is used to feed ANN with refined data, reducing the complexity of the network structure and the learning time.

Other researches aim for supporting engineers during the usage of sustainable manufacturing methodologies. (Zarandi et al., 2011) developed a KBS to preliminary filter materials for shortening the candidates' list for LifeCycle Engineering (LCE) analysis. The input interface asks for candidate material properties and gives the material evaluation. (Duflou et al., 2003) cope with the data availability in the early design phases (functional parameters) for supporting the LCE. These authors developed a KBS that uses product, design and environmental requirements knowledge for adapting general eco-design guidelines to the specific problem situation. In (Vargas Hernandez et al., 2012), the authors developed a KBS to guide engineers in the choice of the most appropriate tool for DfE (Design for Environment). Principles that apply the engineer objectives are the required inputs whereas the output of the system is a list of guidelines referring to specific applications for obtaining the user goals.

A system that takes into account standards and laws for sustainability can be found in (Houe et al., 2007). Authors stress the need for better interpreting environmental standards and laws. In their paper, they build a conceptual model and show how concepts in norms can be modelled as rules based on these concepts. In perspectives, these authors design a decision support system (DSS) that has features such as integration with CAD/CAM or product life-cycle management (PLM) systems, possibility to select different standards and to assess the on-going product design according the selected norms.

To our best of knowledge, no researches deal with the usage of expert knowledge about sustainable manufacturing for identifying change opportunities and for proposing sustainable solutions.

\subsection{Ontologies in manufacturing and sustainability}

The development of KBS in mid ' 80 is the main reason for the use of ontologies in computer science and artificial intelligence (AI) (Freitas et al., 2005). Ontology is an explicit specification of a conceptualization (Gruber, 1993). Through the use of ontologies for representing knowledge, this can be understood, shared and communicated across people and computers (Darai et al., 2010). The development of ontologies as a tool for knowledge representation has been a revolution in knowledge engineering, so that according to (Staab, 2009), AI researchers have highlighted the need of a more robust and theoretically sound engineering ("ontology engineering") which enables knowledge sharing/reuse and formulation of the problem solving process itself. For a $\mathrm{KBS}$, the knowledge base development is the most expensive task (Freitas et al., 2005). Hence, it is easy to understand the great opportunity given by ontologies. In fact, in early KBS, knowledge was about specific tasks while ontologies formalize knowledge about a domain 
improving expertise reusability. Therefore, ontologies are natural candidates as knowledge bases in KBS.

In the manufacturing context, there have been some efforts in developing ontologies, at different levels, for supporting information exchange and reuse, and creation of new knowledge. A consistent number of ontologies developed in this domain are mainly taxonomies (i.e., particular classifications arranged in a hierarchical structure and organized by generalization-specialization relationships or parent-child relationships). Really few research works reached the effective development of a formal ontology.

Some ontology has been developed so far in the field of manufacturing. Lemaignan et al. (2006) propose an ontology applied to manufacturing, named MASON (MAnufacturing's Semantics ONtology). MASON has been built upon three head concepts: entities, operations, and resources. The main applications of this ontology are: 1) to develop architectures and tools for automatic cost estimation; 2) to link a high level ontology with a multiagent framework for manufacturing simulation. To achieve an effective and efficient support to product design decisions, (Wang et al., 2008) proposed an ontological approach for analysing what kinds of manufacturing knowledge are needed for design decisions. An ontology in the domain of manufacturing knowledge has been thus designed by using the ontology development tool Protégé ${ }^{2}$ 3.3.1 with the intention to investigate its application in design decision support. In (Tursi et al., 2009; Panetto et al., 2012), authors have developed a product ontology, named ONTO-PDM, based on two standards, for providing a semantic layer to business, design and manufacturing product-related information (in the section 3.2, a description of this work is presented with more details). The knowledge management in industrial scenarios, instead of its modelling, has been the objective of the Know-Ont ontology of (Harshit Kumar et al., 2010). The proposed ontology is used to provide reusability of stored information in an efficient and effective way.

Quite a few authors have faced the problem of ontologies for sustainability. Many of the sustainability factors in manufacturing do interact, influence, restrict and depend on each other. This complexity is the main reason why an ontology may be a suitable tool to successfully reach the target of a sustainable manufacturing (Kibira et al., 2009). (Reyes-Cordoba et al., 2008) stress the role of knowledge management coupled together with management actions to support decisions concerning the different engineering activities that have to be performed for waste minimisation. The authors adopt an ontology for mapping and organising the whole knowledge to provide an effective way for reducing gaps in the information needed to fully understand the process and identify the signs that point towards waste generation. In (Brilhante et al., 2006) the authors present a very general framework based on an ontology and metadata, in connection with a software implementation, to analyse systems sustainability making use of quantitative and/or qualitative sustainability indicators.
In a preliminary study, (Dori et al., 2005) stress on shifting from an older energy-driven paradigm to a knowledgedriven one related to manufacturing. For building a comprehensive ontology, the authors firstly face the problem of knowledge mapping by adopting an Object Process Methodology-based approach for modelling product lifecycle knowledge. In (Ceccaroni et al., 2004) a decision-support system for wastewater management is presented. The strength of the proposed application is the possibility to manage the complexity of multidisciplinary knowledge necessary for wastewater management in supporting the DSS, particularly for qualitative knowledge. In (Garrido et al., 2011) the authors propose an ontology for impact assessment by including natural language definitions. The system supports an environmental indicator assessment contributing to information about the state of the ecosystem or something relative to it. The same ontology is devised as a support to a decision support system for environment impact assessment.

In literature it is possible to find a lot of ontologies that deal with concepts of product, processes or resources, but in order to be able to identify alternative solutions it is needed to relate this concept with a functional view. Moreover, information about these notions is often managed by several different data sources according different points of view. For the scope of this paper, an ontology is required: the ontology has to be able to align all collected information about this concepts on common semantics as well as to associate these with functions related concepts. For this purpose, in this paper it is extended ONTO-PDM (Panetto et al., 2012) associating existing concepts (processes, resources and product view) with proper concepts to express functional requirements.

\subsection{The concept of function}

In order to suggest alternatives, knowledge about changes propagation in the product is required. Therefore, to manage changes in product design or manufacturing processes, it is necessary to deeply understand functional dependencies (Kocar et al., 2010), because it is needed to propose changes that not bias the original product purpose. To this aim, it is required to identify why specific product parts, manufacturing processes, resources are used and how they satisfy the required functions. In the next section, literature works on function representation are presented.

The definition of the function concept has been the subject of many researches. (Umeda et al., 1990) wanted to clarify notions of behaviour, structure and function. For these authors, a function is a "description of behaviour abstracted by humans through recognition of the behaviour in order to utilise it". (Deng, 2002) proposes an input-output action transformation scheme for semantic function representation. This representation method decomposes functions in three basic transformations: transformation of state, of object (intended input in intended output) and of action (driving input in functional output). In (Kumar et al., 1998), authors propose an ontological representation of function designed for 
diagnosis. In this representation, functions are behaviour abstractions and their definition is context independent. (Luca Chittaro et al., 1998) unify different perspectives of the concept of function that is viewed as a relation among a specific system, the behaviour of it in a specific context and its purpose. (Chandrasekaran et al., 2000) use a device ontology (ontologies on functional design, based on what components or devices are able to do) to stress the difference between two visions: i) device-centric, in which functions are described in terms of devices properties and behaviours; ii) environment-centric, in which functions are described as effects of devices on the world around them. In (Kitamura et al., 2004), authors stress the importance of ontological modeling (see next section) to support the formalization of functions. They propose a framework, based on four types of functional schematization. Functions in this framework are associated by means of three main relations. The $i s-a$ relation of functions describes generalizations between functions. The isachieved-by (part-of) relations associate macro and micro functions. The $i s-a$ relations are also used to define ways of function achievement trees.

In literature there are different systems that use the concept of function. (Bhatta et al., 1997) presented IDEAL, a system that, starting from functional requirements and structural constrains, uses knowledge about design and causal patterns, for assigning or adapting a design solution that fulfil requirements. In (Bracewell et al., 2001) functional decomposition and satisfaction rules are used to represent design knowledge. Rules contain knowledge about ways that parts or networks of these can perform single functions or functions structures. (Chandrasekaran et al., 1993) investigate the use of functional representation for diagnostic generation, design verification and redesign. (L. Chittaro et al., 1993) propose an approach for using functional and teleological (the teleology of a system is defined as the specification of the goals assigned to it by the designer) knowledge within the multi-modelling technique for problem solving in physical systems. They show a system called DYNAMIS, which copes with operator diagnosis, diagnosis focusing and functional conflict recognition. (Malmqvist, 1997) worked on a function-based system to store history design (why the solution has been selected). In this latter paper, the authors extend Function-means Trees (that shows how particular means for solving a function lead to requirement on a sub-function) with constraints on goals, extended definition of functions and concepts on effects of different means on requirements.

In the current paper, authors propose to use the functional representation of a product, processes and resources as a pivot for proposing sustainability-based changes in the manufacturing processes, without biasing product functionalities. Functions (and other related concepts) need to be associated to product, processes and resource notions for permitting reasoning about manufacturing sustainability knowledge.

\section{THE PROPOSED APPROACH}

In this paper it is proposed a system based on an ontology in which sustainable manufacturing knowledge is associated with concepts of resources, processes, product and their functions. This model allows formalizing required knowledge for identifying change opportunities and proposing new solutions taking into account the sustainability of manufacturing. Java code allows interfacing users with the knowledge base and the inference engine. The OBS that exploits this model uses enterprise information (product, resources, processes) for supporting engineers with relevant propositions. In (Giovannini et al., 2012), authors already proposed a model able to manage knowledge about sustainable manufacturing. In that case, links between solutions and functions have to be performed manually. That is to say, there was not a way to automatically infer functions starting from product information. In this paper a model able to associate functions and sustainable knowledge is proposed, to perform inference for supporting product, process and resources functions associations. The function and sustainable constraints representations allow detailing solutions respecting required product functionalities.

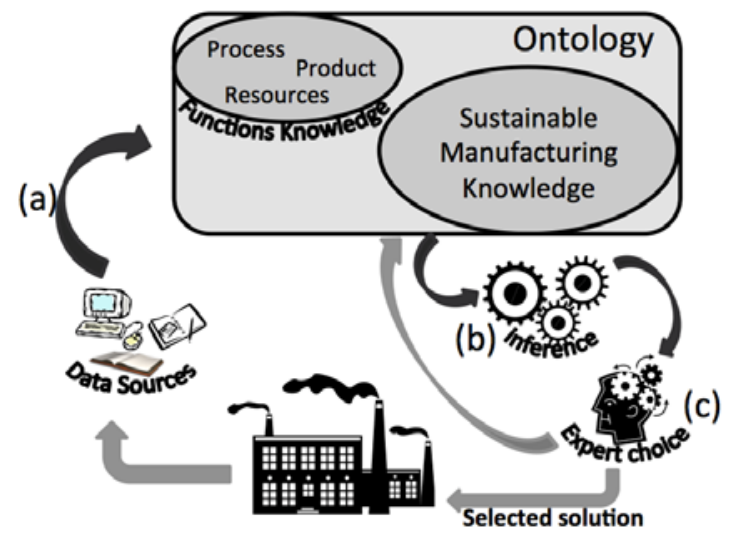

Fig. 1 - The path from ontology instantiation to the solution choice (black arrows point out automatic tasks).

The first step of our approach is to collect information about the product and related resources and processes initially planned for its manufacturing. Mappings between this data and semantics allow the instantiation of the ontology (Fig. 1 (a)). The ontology contains detailed knowledge about sustainable manufacturing and functions of manufacturing processes and resources. This knowledge permits to infer, by means of an inference engine, functions of entities (resources, processes, product parts) described by mapped information. The inference engine uses sustainable manufacturing knowledge in the ontology to infer alternative design and/or manufacturing processes solutions (Fig. 1 (b)). Solutions are based on identified functions. At the end, an expert accepts or rejects single suggestions until building a feasible sustainable solution (Fig. 1 (c)). 


\subsection{Functional decomposition}

In our system, functions are pivots for deciding changes in manufacturing. A change proposal must not bias product functionalities, which are stored in other alternative proposals. Links between concepts of product, processes and resources with related functions are here modelled. It is used the definition of function in (Umeda et al., 1990)as an abstraction of a behaviour. Moreover, a function can be represented by means of an input-output transformation (Deng, 2002). A set of rules is employed in order to associate parameters and properties of inputs (processes, resources, product parts) with functions effects (results that are expect to be achieved by the function realization) (Fig. 2). In order to represent relations between functions, associations as defined in (Kitamura et al., 2004) are used. Generalizations and is-composed-by relations characterize associations between functions. The former are is-a relations that allow formalizing functions hierarchies. The latter allow formalizing functional decompositions. The concept of means to achieve a function is expressed as way-of-achievement concepts in order to distinguish alternatives for achieving same functions. Means to achieve a function are parts of hierarchies (is-a trees) of detail alternative solutions for the achievement of a function. Each way-of-achievement can be decomposed in others functions or can be a trees leaf. Each function and way-of-achievement is associated to its function effects that are expressed as a set of range values of function output.

Each node can refer to a set of resources and processes: resources properties and processes parameters are inputs that determine function effects (outputs) on the basis of expressed rules. Resources and/or processes are eligible to achieve a function if - instantiating these rules with their properties and/or parameters, or results _ are in the range values defined for the function effects.

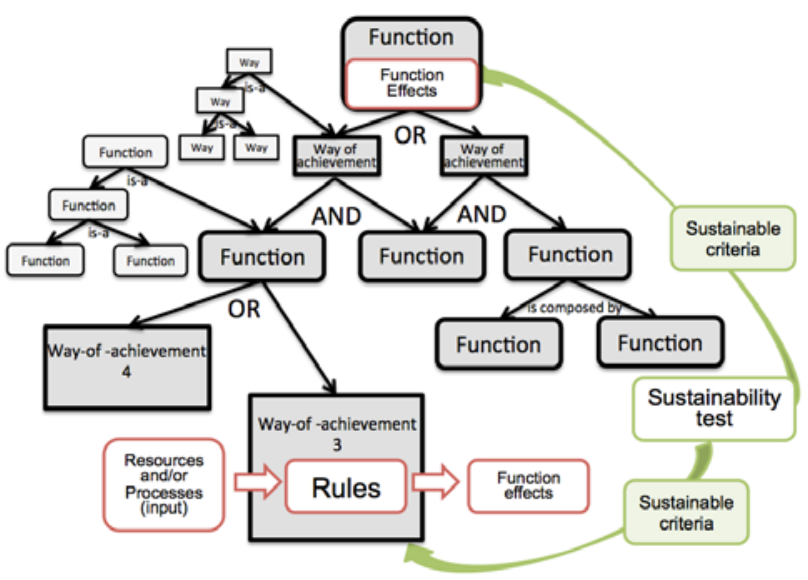

Fig. 2 - Relations between functions and sustainable manufacturing constraints.

In this interpretation, to achieve sustainable manufacturing is required a further set of criteria on a function to be fulfilled. It is possible to identify an ordinary way and a sustainable way to achieve the functional requirements. To obtain effects on sustainability aspects, it is needed to associate concepts related to product configurations, part features, processes, their parameters, resources and their consumption with their sustainability characteristics (durability, recyclability, energy consumption, etc.). Representing sustainable manufacturing as criteria on function allows to take into account the resource and/or process usage and verify if the solution is compliant to those defined manufacturing sustainability criteria. In fact, a solution that seems to be smart if it is employed in a specific scenario could be bad when combined with a different one. Linking knowledge about sustainable manufacturing with the concept of function of product, process and resources allows performing propositions usage-aware.

A sustainable solution concerns information about resources to use, resources quantity, resources way to use, processes, process parameters and product design.

\subsection{Ontology extension}

The intention in our system is to exploit all those useful product- and manufacturing-related information for proposing solutions that influence the sustainability. Required knowledge assisting experts in design is related to product, manufacturing processes and resources. In each enterprise, information about these concepts is managed by heterogeneous applications. Users and software have to interoperate according to this shared heterogeneous information. This heterogeneity might cause a "babel tower effect" that can make manufacturing sustainability culture harder to diffuse. To solve the information sources heterogeneity issue, (Tursi et al., 2009; Panetto et al., 2012) proposed a product-centric information view. The same authors developed the ONTOPDM product ontology extending and formalising this concept. ONTO-PDM is a domain ontology based on two standards, STEP - PDM (Ungerer et al., 2002) and IEC 62264 (ISO/IEC, 2002). In this paper, models from the IEC 62264 as part of ONTO-PDM are used, in order to semantically align product, manufacturing processes and resources from different sources. This standard provides a product view and also conceptual models about equipment, materials, resources and processes. It is enriched the semantic of this part of ONTO-PDM using OWL formalisms (Ontology Web Language (McGuinness et al., 2004)).

In this work, concepts (Erreur! Source du renvoi introuvable.) from the Product Definition, Product Segment, Material, Equipment and Personnel models are used and extended. In the Product Definition Model, each product is expressed as a set of product segments. These segments describe jobs consisting of one or more work elements. Each product segment is related only to a specific product and it is associated to information concerning segment parameters, relationships with other segment and resources (material, equipment and personnel) required to manufacture a part. A product segment makes a reference to one or more process segments. The collection of product segments is detailed in order to provide required information for production planning and scheduling. Knowledge about product 
(configurations, part features, etc.) and related functions are formalized in this model as subclasses of the IEC Product Segment class and related Product Function class. In the Process Segment Model, a process segment is a set of resource capabilities required to implement a phase of manufacturing, referred to as process segment which is product-independent. In the model, segments are lists of parameters, resources (material, personnel and equipment) and related quantities required for the process. Material, Equipment and Personnel models contain information about resources. Structures of models are very similar: they are always presenting classes related to resources, groups of resources with similar properties, resources properties and classes defining tests for similarity behaviour and their relative results.

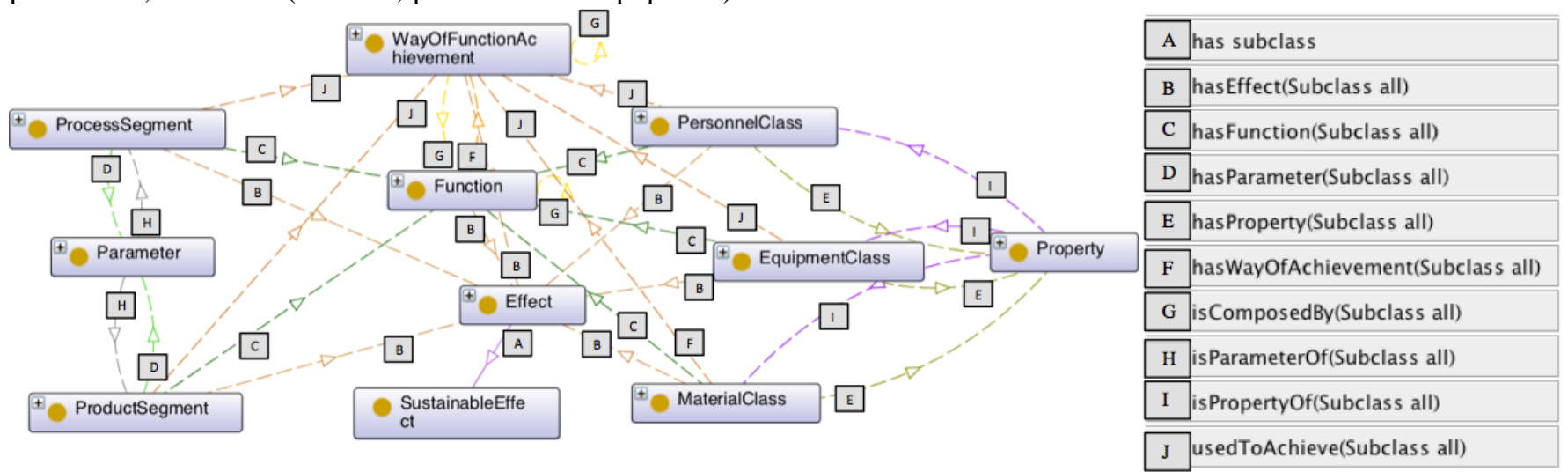

Fig. 3 - Ontology excerpt from Protégé 4 (http://protege.stanford.edu): relations between functions effects and other classes.

The models are formalized in OWL using SWRL rules (Semantic Web Rule Language - (Horrocks et al., 2004)). Using an OWL inference engine, concepts and rules can be verified to check their consistency, but it is not possible to formalize rules that are able to work with unknown individuals. That is to say, it is not possible to infer a new value of a property starting from a formula defined in a rule. This causes a problem for the formalization of functions inputs/outputs rules. For this aim, appropriate SQWRL (Semantic Query-enhanced Web Rule Language) (O’Connor et al., 2009) queries are used for formalizing this type of rules. The advantage is that it is then possible to associate terms of formulas with ontology concepts. Java codes are required to interpret queries results and to add these as new properties.

Erreur ! Source du renvoi introuvable. shows the part of the ontology concerning the relations between functions, product, process and resources concepts. Functions are described by sets of effects that are defined as range of values. Mappings between information and the ontology allow to instantiate resources and related properties, product parts and processes and related parameters. On the basis of these values and the knowledge about functions and with proper SWRL rules, the inference engine is able to infer hasFunction (or usedToAchieve) relations between introduced instances and functions (or way-of-functionachievement). Starting points are product parameters values that are compared with functions effects values (e.g. R1).

\footnotetext{
R1. Function(fixedFunction) $\Lambda$ Effect(fixedEffect) $\Lambda$ hasEffect(fixedFunction, fixedEffect) $\Lambda$ Value(?v1) $\Lambda$ hasEffect(fixedFunction,?v1) $\Lambda$ hasValue(fixedEffect, ?v1) $\Lambda$ ProductSegment(?ps) $\wedge$ Parameter(fixedParameter) $\Lambda$ hasParameter(?ps, fixedParameter) $\Lambda$ Value(?v2) $\Lambda$ hasParameter(?ps, ?v2) MhasValue(fixedParameter, ?v2) $\Lambda$ unitOfMeasure(?v2, fixedUnit) 1 hasMinValue(?v1, ?vmin)
}

\section{$\Lambda$ value(?v2, ?val2) 1 swrlb:greaterThanOrEqual(?val2, \\ ?vmin) $\rightarrow$ hasFunction(?ps, fixedFunction)}

In the same way, inferences on other hasFunction relations (for product components, processes and resources) are evaluated comparing function effects (outputs) for the instances values (inputs are material properties, processes parameters, etc.) that are calculated through function (and way of function achievement) related rules, formalized in SWRL (e.g. R2).

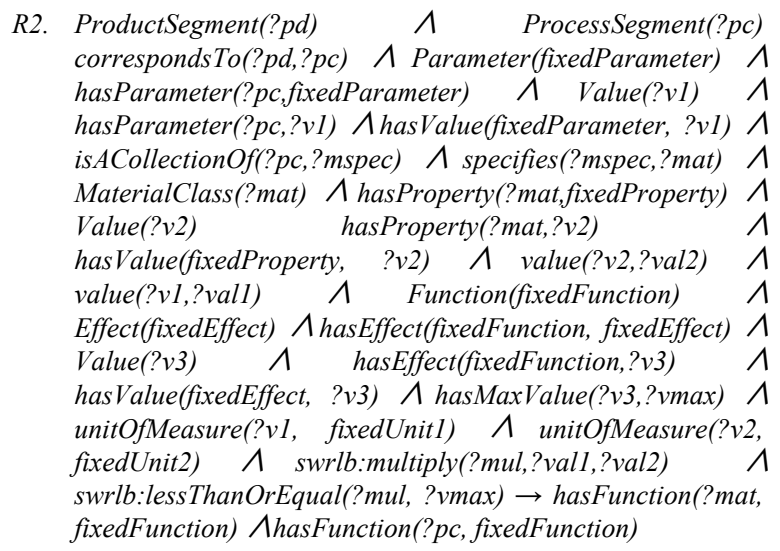

R1 and R2 allow defining relations between instance of product, resources, processes and their functions. On the basis of these relations, the alternatives inference can start. SWRL rules verify if other processes, product parts and resources - that can instantiate functions rules (i.e. if there is a value associated to their properties/parameters to reckon results) - lead to values compliant to function effects ranges values (see e.g. R3). The same kind of verification is performed for sustainable functions effects. In this case the fulfilment of sustainable constraints is added on conditions required for function effects. That is to say, a sustainable alternative needs to satisfy also functional requirements (expressed by function effects). 
These rules allow composing alternatives: they permit inference of relations between functions rules inputs (processes parameters, products parts parameters and/or resources properties) and inputs with satisfied functions.

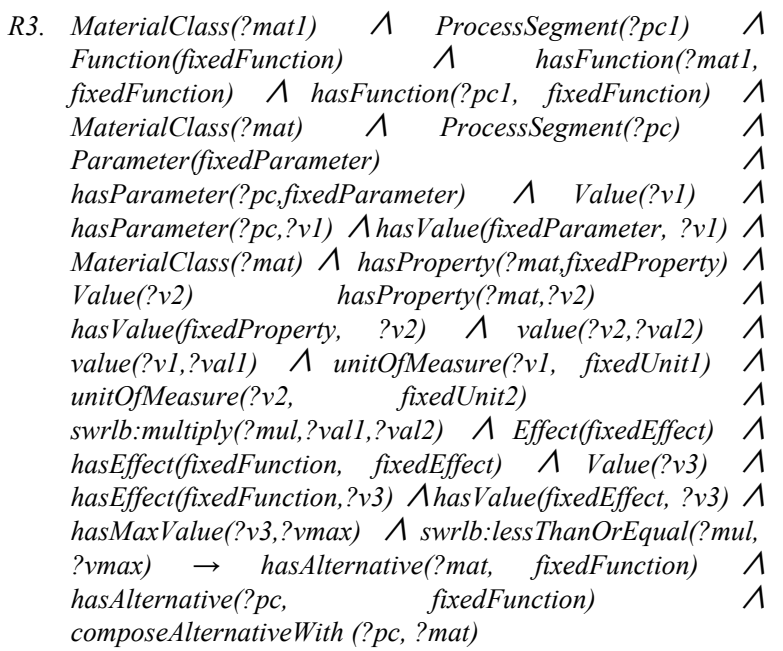

Proper SQWRL queries (R4) allow to calculate sustainable alternatives details for required functions: information about input parameters and functions effects.

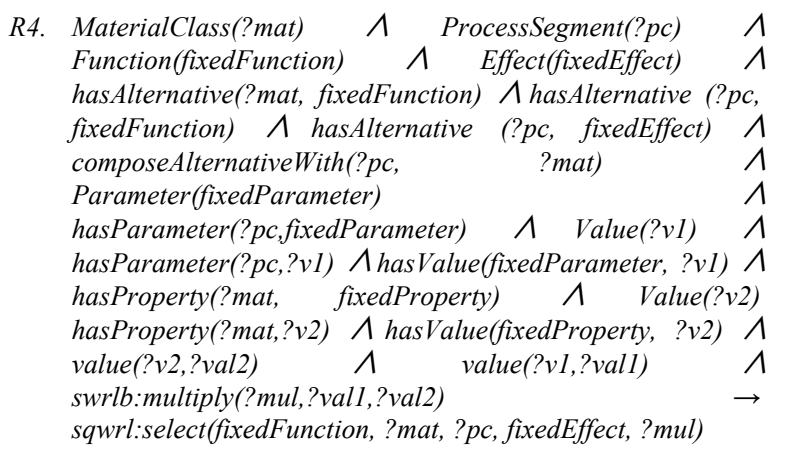

The formalised rules have the same structure and scope for inferences about way of function achievement and sustainable manufacturing criteria. Finally, for each function, achievement or sustainable manufacturing rule, it is needed to formalize three SWRL rules and a SQWRL query: a) R1 and R2 rules for associating individuals introduced by mappings; b) an R3 rule for looking for alternatives; c) an R4 query for calculating function effects for newer alternatives. In the functional decomposition, function inputs can be outputs of one or more other functions. In this case, it is needed the same number of rules (two SWRL and one SQWRL) for each level of the tree that links basic functions (or way-to-achieve) to produce required function effects.

In our approach, sustainable alternatives can be associated to a evaluation of the sustainable solutions, even though it is not possible to propose an evaluation method for sustainability. By formalizing manufacturing sustainability using constraints to achieve sustainable functional effects, it is possible to add evaluation criteria based on resources, manufacturing processes or their impact for a specified function.

\section{INDUSTRIAL CASE}

In this section, an industrial case is here used to explain the instantiation of the extension of the ontology and to test the inferences based on the SWRL rules/SQWRL queries above presented. The case concerns a multinational company working in the sector of air conditioning and refrigeration units for industrial and commercial use. Currently the Trane Company is dealing with the sustainability issue of its products. Trane products are characterized by modularity (see Fig. 3 (a), (b)); every module needs several sheet metal parts as in Fig. 3 (c).

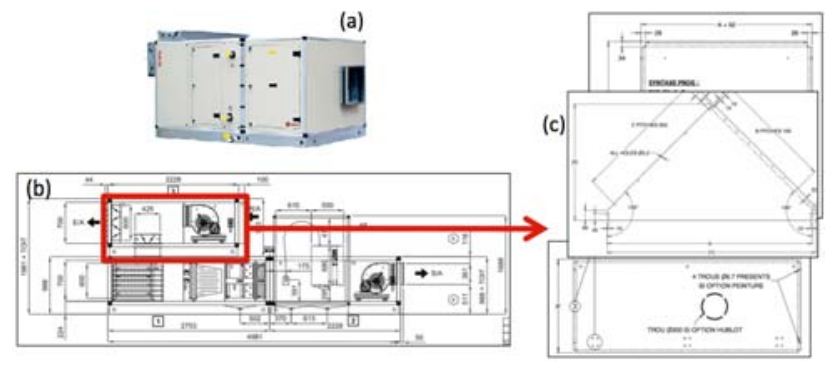

Fig. 3 - Trane product modularity and punched/bended parts.

Sheet metal parts are at least involved in a punching and a bending process. Here we will concentrate only on the manufacture of panels that compose the external covering of each product module. Each panel is usually (one of the configuration option is) made of two skins of galvanized steel. Each skin is punched and bended. After machining operations, skins are injected with isocyanate/polyol foam.

Each panel fulfils the following functional requirements: acoustic isolation, thermic isolation, resistance at weathering agents; bending rigidity. Every function has been decomposed till elementary ones. In Fig. 4 the decomposition of thermal and acoustic insulation requirements is shown. At each level, dependences between functions of same level are formalized to make feasible to infer the effect of a change on other processes, resources or product parts involved in the fulfilment of product requirements. To make possible inferences in the system, these functions have to be expressed by means of the panel parameters (e.g. resistance at bending, resistance to corrosion measured as time resistance in salted moisture, conductivity, noise reduction, etc.) (Fig. 4). Product is associated automatically (by rules like R1) to its functions, by comparing its properties values with allowed ranges for functions. For instance, to be associated with the function resistance at weathering agents, panel must have a resistance to corrosion value greater than 500h in salted moisture. In the same way, rules permit to identify functions fulfilled by processes and/or resources. For instance, rules like R2 are instantiated for foam injection for acoustic insulation. The inject foam function allows achieving an insulation layer with a desired density. This density depends of foam mix properties, injection foam flow rate and process time. This density biases the desired acoustic insulation value. Similar rules types are expressed 


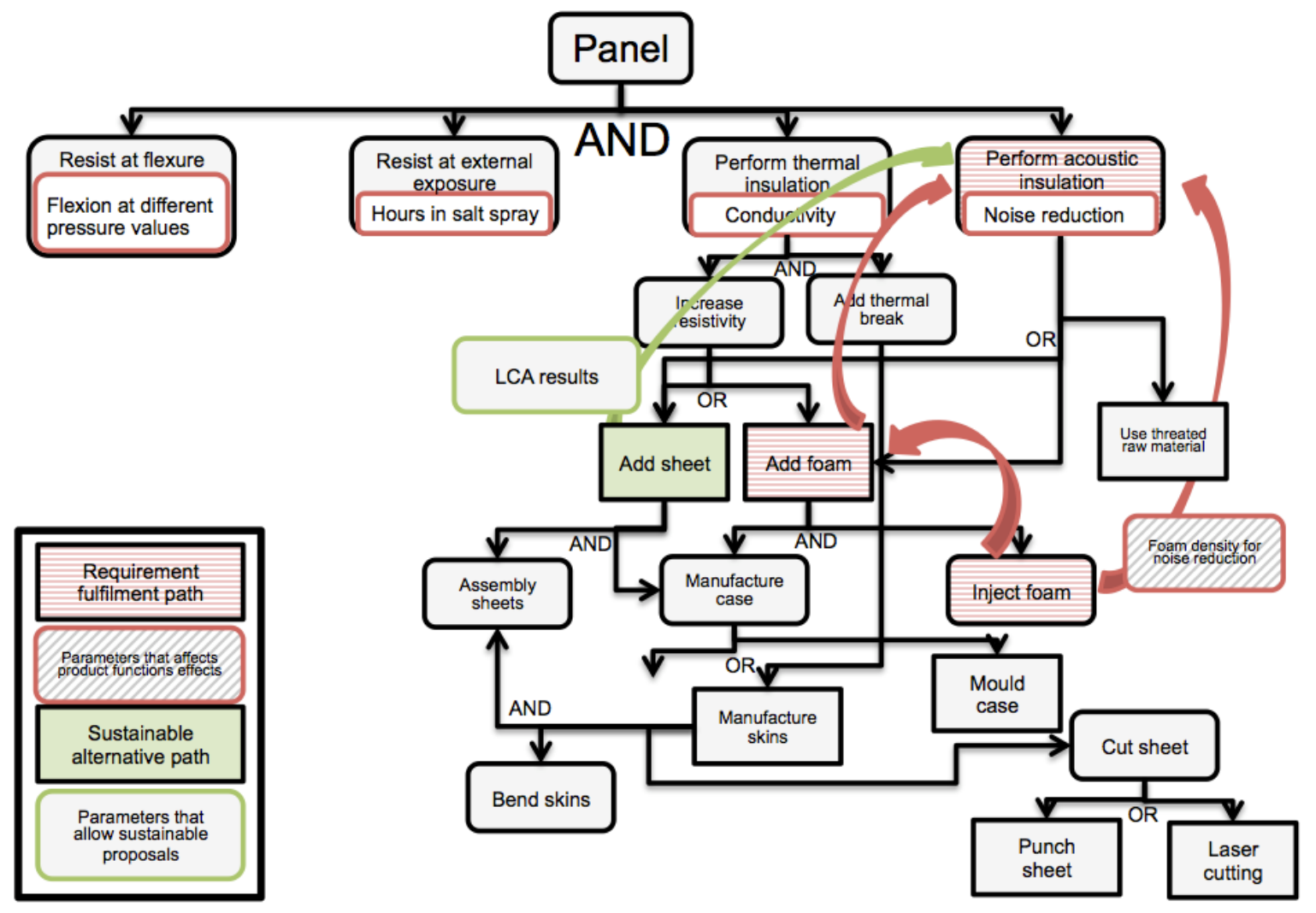

Fig. 4 - Relations between Trane panels functions and way of functions achievement.

for others solutions to achieve the same function (e.g. add insulation sheet). Sustainable constraints on insulation function can be achieved from a life-cycle assessment (LCA). Here in fact it is possible to find relation between materials features and their environmental impact. Alternatives that respect functional and sustainable constraints are inferred by R3 type rules. R4 queries allow visualizing alternative solutions details. In this case, natural insulation materials (e.g. sheep wall, hemp and cotton) are inferred. For this inferred solution, an assembly process for enclosing the layer between the panel skins replaces the injection process. On the basis of materials specifications and thermal/acoustic insulation rules, parameters of required modifications are inferred.

\section{CONCLUSION AND PERSPECTIVES}

In this paper, a formal approach and its related software tool able to identify sustainable opportunities in product and manufacturing processes design is presented. An extension of a product-centric ontology based on a functional vision is proposed. In doing so, concepts about all knowledge needed for this task are described and required information from heterogeneous sources to common semantics is aligned. Sustainability is perceived as a different and more comprehensive way to obtain functions, taking into account impacts on environment and society. In order to be acceptable, an alternative has to fulfil all functional requirements while maintaining all required initial functionalities of a product. It is thus considered sustainable if it is compliant to given formalized manufacturing conditions.
Two critical points of the approach are: the definition of functions and the formalisation of sustainable manufacturing rules. To infer knowledge about functions and sustainable solutions, it is in fact needed a high level of detail for function effects definition and in product, processes and resources descriptions. Moreover, if it is required deployment of the ontology on more production sites, differences in the formalization of sustainable manufacturing constraints should be found. For instance, different applied norms and/or standards lead to different interpretation of sustainability criteria. Future researches should be oriented on how an OBS can manage this type of issues in this domain.

Currently, alternative solutions are adapted to information but they ignore dynamics of enterprise business processes. The inference engine considers as feasible a solution that respects all functional constraints, but constraints of a local production site can narrow its applicability. An interesting perspective should be the analysis of how sustainability solutions can be fitted to enterprises processes, in order to make possible a more effective support for the deployment. This can be not only an adaptation, but it is possible to find strategies to enhance solutions effects on the basis of business processes knowledge. Finally, output information can be mapped directly with enterprises databases for further reducing the time to deployment.

\section{Aknowledgement}

This paper has been developed under the partial granting from GALILEO Project - n. 25974QF "Product-centric interoperability for systems integration in a sustainable environment". 


\section{REFERENCES}

Bhatta, S. R and Goel, A. K (1997), A Functional Theory of Design Patterns, 294-300, in: International Joint Conference On Artificial Intelligence.

Bracewell, R. H. and Wallace, K. M. (2001), Designing a Representation to Support Function-means Based Synthesis of Mechanical Design Solutions. Proceedings of ICED01, Glasgow, Scotland, Vol. "Design Methods: 275-282.

Brilhante, V., Ferreira, A., Marinho, J. and Pereira, JS (2006), Information Integration Through Ontology and Metadata for Sustainability Analysis, , in: Proc. of the 3rd biennial meeting of the International Environmental Modelling and Software Society.

Ceccaroni, L., Cortés, U. and Sanchez-Marre, M. (2004), OntoWEDSS: Augmenting Environmental Decision-support Systems with Ontologies. Environmental Modelling \& Software, 19(9): 785-797.

Chandrasekaran, B., Goel, A. K and Iwasaki, Y. (1993), Functional Representation as Design Rationale. Computer, 26(1): 48-56.

Chandrasekaran, B. and Josephson, J. R (2000), Function in Device Representation. Engineering with computers, 16(3): 162-177.

Chittaro, L., Guida, G., Tasso, C. and Toppano, E. (1993), Functional and Teleological Knowledge in the Multimodeling Approach for Reasoning About Physical Systems: A Case Study in Diagnosis. Systems, Man and Cybernetics, IEEE Transactions on, 23(6): 1718-1751.

Chittaro, Luca and Kumar, Amruth N (1998), Reasoning About Function and Its Applications to Engineering. Artificial Intelligence in Engineering, 12(4): 331-336.

Darai, D.S., Singh, S. and Biswas, S. (2010), Knowledge Engineering-an Overview. International Journal of Computer Science and Information Technologies, 1(4): 230-234.

Deng, Y. M (2002), Function and Behavior Representation in Conceptual Mechanical Design. AI EDAM, 16(05): 343-362.

Dori, D. and Shpitalni, M. (2005), Mapping Knowledge About Product Lifecycle Engineering for Ontology Construction via Object-process Methodology. CIRP Annals-Manufacturing Technology, 54(1): 117-122.
Duflou, J., Dewulf, W., Sas, P. and Vanherck, P. (2003), Pro-active Life Cycle Engineering Support Tools. CIRP Annals - Manufacturing Technology, 52(1): 29-32.

Flouris, G., Plexousakis, D. and Antoniou, G. (2006), Evolving Ontology Evolution. SOFSEM 2006: Theory and Practice of Computer Science: 14-29.

Freitas, F., Stuckenschmidt, H. and Noy, N.F. (2005), Ontology Issues and Applications. Journal of the Brazilian Computer Society, 11(2): 5-16.

Garrido, J. and Requena, I. (2011), Proposal of Ontology for Environmental Impact Assessment: An Application with Knowledge Mobilization. Expert Systems with Applications, 38(3): 24622472.

Giovannini, A., Aubry, A., Panetto, H., Dassisti, M., El Haouzi, H. and others (2012), Knowledge-Based System for Manufacturing Sustainability In: 14th IFAC Symposium on Information Control problems in Manufacturing, INCOM'2012, May 23-15, 2012, Bucharest, Romania. Elsevier, 14, 1333-1338, IFACPapersOnline.

Gruber, T.R. (1993), A Translation Approach to Portable Ontology Specifications. Knowledge acquisition, 5(2): 199-220.

Harshit Kumar, H.K. and Pil Seong Park, P.S.P. (2010), Know-Ont: A Knowledge Ontology for an Enterprise in an Industrial Domain. International Journal of Database Theory and Application, 3(1): 23-32.

Horrocks, I., Patel-Schneider, P.F., Boley, H., Tabet, S., Grosof, B. and Dean, M. (2004), SWRL: A Semantic Web Rule Language Combining OWL and RuleML. W3C Member submission, 21: 79.

Houe, R. and Grabot, B. (2007), Knowledge Modeling for Eco-design. Concurrent Engineering, 15(1): 720.

ISO/IEC (2002), IEC 62264 - Enterprise-control System Integration, Part 1: Models and Terminology, Part 2: Model Object Attributes. in: Geneva.

Iwata, K. (1988), Application of Expert Systems to Manufacturing in Japan. The International Journal of Advanced Manufacturing Technology, 3(3): 23-37.

Kibira, D., Jain, S. and Mclean, C. (2009), A System Dynamics Modeling Framework for Sustainable Manufacturing, , in: Proceedings of the 27th Annual System Dynamics Society Conference. 
Kitamura, Y., Kashiwase, M., Fuse, M. and Mizoguchi, R. (2004), Deployment of an Ontological Framework of Functional Design Knowledge. Advanced Engineering Informatics, 18(2): 115127.

Kocar, V. and Akgunduz, A. (2010), ADVICE: A Virtual Environment for Engineering Change Management. Computers in Industry, 61(1): 1528.

Kumar, Amruth N. and Upadhyaya, Shambhu J. (1998), Component-ontological Representation of Function for Reasoning About Devices. Artificial Intelligence in Engineering, 12(4): 399-415.

Lemaignan, S., Siadat, A., Dantan, J.Y. and Semenenko, A. (2006), MASON: A Proposal for an Ontology of Manufacturing Domain, 195-200, in: Distributed Intelligent Systems: Collective Intelligence and Its Applications, 2006. DIS 2006.

Malmqvist, JOHAN (1997), Improved Function-means Trees by Inclusion of Design History Information. Journal of Engineering Design, 8(2): 107-117.

McGuinness, D.L. and Van Harmelen, F. (2004), OWL Web Ontology Language Overview. W3C recommendation, 10: 2004-03.

O’Connor, MJ and Das, AK (2009), SQWRL: a Query Language for OWL, , in: OWL: Experiences and Directions (OWLED), Fifth International Workshop.

Panetto, H., Dassisti, M. and Tursi, A. (2012), ONTOPDM: Product-driven ONTOlogy for Product Data Management Interoperability Within Manufacturing Process Environment. Advanced Engineering Informatics, 26 (2): 334-348, Elsevier.

Pham, DT and Pham, P.T.N. (1988), Expert Systems in Mechanical and Manufacturing Engineering. The International Journal of Advanced Manufacturing Technology, 3(3): 3-21.

Pineda-Henson, Ruby and Culaba, A.B. (2002), Developing an Expert System for GP Implementation, 9-11, in: Proceedings of the 2nd World Conference on Green Productivity.

Reyes-Cordoba, A P, Sharratt, P N and ArizmendiSanchez, J A (2008), Contribution of Knowledge Management for the Implementation of Waste Minimisation Measures into Process Industries. Process Safety and Environmental Protection, 86(5): 375-388.
Staab, S. (2009), Handbook on Ontologies. Springer Verlag.

Tursi, A., Panetto, H., Morel, G. and Dassisti, M. (2009), Ontological Approach for Products-centric Information System Interoperability in Networked Manufacturing Enterprises. Annual Reviews in Control, 33(2): 238-245.

Umeda, Y., Takeda, H., Tomiyama, T. and Yoshikawa, H. (1990), Function, Behaviour, and Structure. Applications of artificial intelligence in engineering $V$, 1: 177-194.

Ungerer, M. and Buchanan, K. (2002), Usage Guide for the STEP PDM Schema V1. 2, Release 4.3. See also URL http://cax-if. de/documents/pdmug release4_3.pdf.

Vargas Hernandez, N., Okudan Kremer, G., Schmidt, L.C. and Acosta Herrera, P.R. (2012), Development of an Expert System to Aid Engineers in the Selection of Design for Environment Methods and Tools. Expert Systems with Applications, 39(10): 9543-9553.

Wang, K. and Tong, S. (2008), An Ontology of Manufacturing Knowledge for Design Decision Support, 1-5, in: Wireless Communications, Networking and Mobile Computing, 2008. WiCOM'08.

Zarandi, Mohammad, Mansour, Saeid, Hosseinijou, Seid and Avazbeigi, Milad (2011), A Material Selection Methodology and Expert System for Sustainable Product Design. The International Journal of Advanced Manufacturing Technology, 57(9): 885-903.

Zhou, Chang-Chun, Yin, Guo-Fu and Hu, Xiao-Bing (2009), Multi-objective Optimization of Material Selection for Sustainable Products: Artificial Neural Networks and Genetic Algorithm Approach. Materials \& Design, 30(4): 12091215. 